\title{
Congenital fibrinogen deficiency
}

INSERM

\section{Source}

INSERM. (1999). Orphanet: an online rare disease and orphan drug data base. Congenital fibrinogen deficiency. ORPHA:335

Congenital deficiencies of fibrinogen are coagulation disorders characterized by bleeding symptoms ranging from mild to severe resulting from reduced quantity and/or quality of circulating fibrinogen. Afibrinogenemia (complete absence of fibrinogen) and hypofibrinogenemia (reduced plasma fibrinog en concentration) (see these terms) correspond to quantitative anomalies of fibrinogen while dysfibrinogenemia (see this term) corresponds to a functional anomaly of fibrinogen. Hypo- and dysfibrinogenemia may be frequently combined (hypodysfibrinogenemia). 